\title{
The Study of Blankit Concentration as an Unauthorized Additive in Hamadan Bakeries and Risk Assessment of Food Consumption
}

\section{Ghorban Asgari (PhD) ${ }^{1}$, Abdolmotaleb Seid Mohammadi (PhD) ${ }^{1}$, Javad Faradmal $(\mathrm{PhD})^{2}$, Mohammad Jamil Moradi (MSc) ${ }^{3}$, Khadije Yari (MSc) ${ }^{3, *}$}

${ }^{1}$ Associate Professor, Social Determinants of Health Research Center (SDHRC) and Department of Environmental Health Engineering, School of Public Health, Hamadan University of Medical Sciences, Hamadan, Iran

${ }^{2}$ Associate Professor, Department of Biostatics and Epidemiology, Faculty of Public Health, Hamadan University of Medical Sciences, Hamadan, Iran

${ }^{3}$ Master of Environmental Health Engineering, Hamadan University of Medical Sciences, Hamadan, Iran

* Corresponding Author: Khadije Yari, Hamadan University of Medical Sciences, Hamadan, Iran. Tel: 09188161014; Email: Khadije.yari56@gmail.com

\section{Abstract}

Received: 25/01/2018

Accepted: 30/04/2018

How to Cite this Article:

Asgari G, Seid Mohammadi A, Faradmal J, Moradi MJ, Yari K. The Study of Blankit Concentration as an Unauthorized Additive in Hamadan Bakeries and Risk Assessment of Food Consumption. Pajouhan Scientific Journal. 2018; 16(4): 21-27. DOI: $10.29252 / p s j .16$. 4.21
Background and Objectives: Using additives such as Balnkit, to increasing the quality color of food and for the fermentation and early preparation of bread dough, has increased in recent years. The purpose of this study was to investigate the concentration of Blankit in Hamadan breads production and risk assessment of food consumption during 2016. Materials and Methods: In this descriptive-analytical study, Balnkit, concentration in breads produced in Hamadan in 2016 was determined. A total number of 85 samples were randomly collected from all bakeries in two steps. The concentration of Blankit was determined according to ISIRI guideline using spectrophotometer in $560 \mathrm{~nm}$. Then for the evaluation of risk assessment of food consumption, the value of target hazard quotients (THQ) was calculated.

Results: The Blankit was not found in $97 \%$ of samples and only $3 \%$ of samples (Lavash bread) have the Blankit. The calculation of the THQ index showed that value of THQ was 0.0041 whose value is less than 1 and the consumption of bread with this concentration will not endanger.

Conclusions: The results of this study showed that the addition of Blankitin bread processing, with regard to the concentrations determined and eliminating it from bread due to the heat, does not pose a threat to the health of the people.

Keywords: Blankit; Bread; Hamadan 


\section{بررسى ميزان بلانكيت به عنوان يك افزودنى غير مجاز در نان نانوايىهاى شهرستان

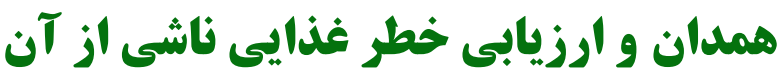

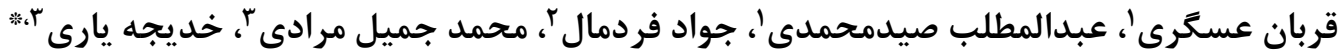

' دانشيار، مركز تحقيقات عوامل اجتماعى موثر بر سلامت، كروه مهندسى بهداشت محيط، دانشكده بهداشت، دانشعاه علوم يزشكى همدان، همدان،

r r دانشيار، تروه آمار زيستى، دانشكده بهداشت، دانشكاه علوم يزشكى همدان، همدان، ايران

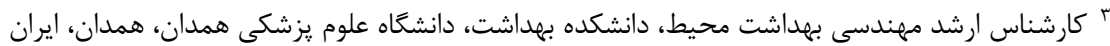

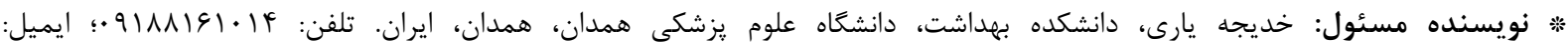
Khadije.yari56@gmail.com

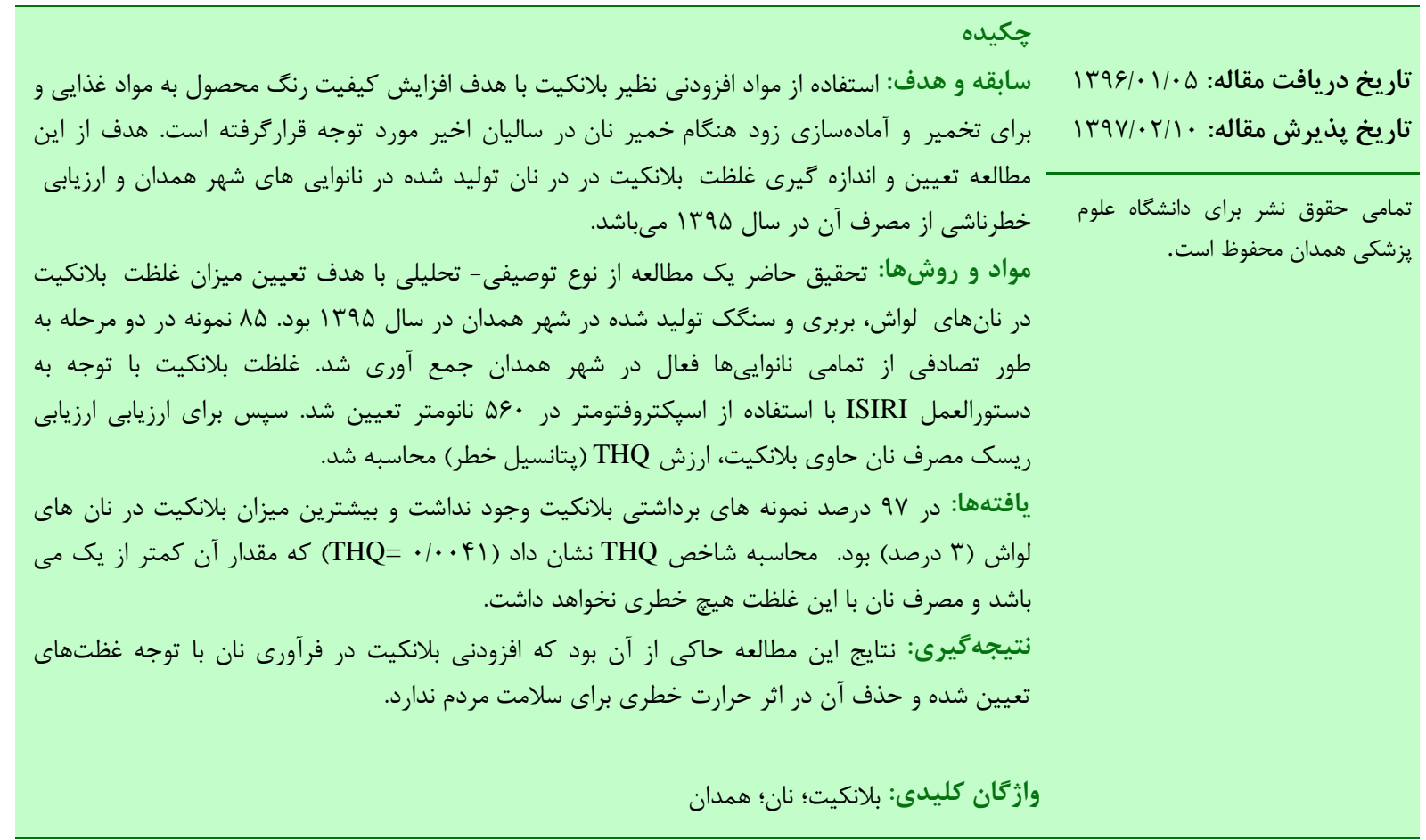

مقلدمه

افزودنىهاى مواد غذايى هستند، اما متخصصان با توجه به امكان زنده ماندن و تكثير ميكروب هاى بيمارى زا دراد در مواد غذايى معتقدند اين تركيبات نكمهدارنده ضد ميكروبى همراه بان عمليات اجرايى مناسب نقش مفيدى در تامين ايمنى مواد

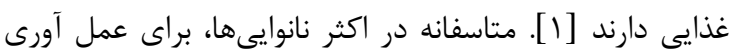
نان بصورت مصنوعى به منظور تسريع در كوتاه كردن فرآيند

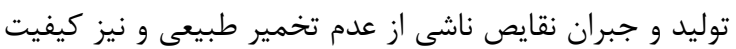

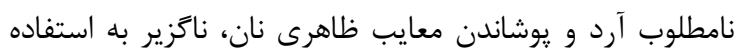

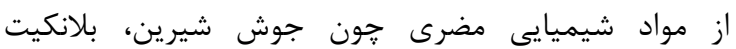
(هيدروسولفيت سديم)، نمك طعام اضافى براى كاهش سياليت

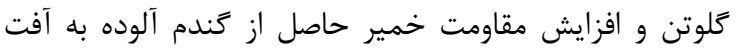

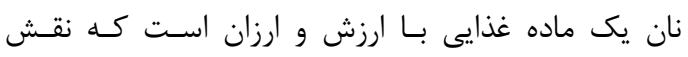

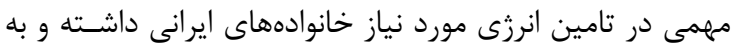

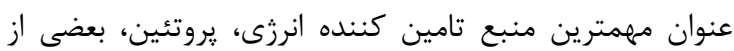

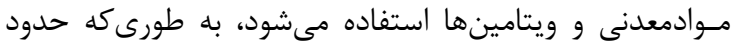

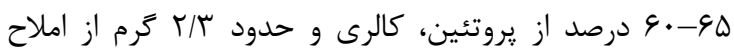

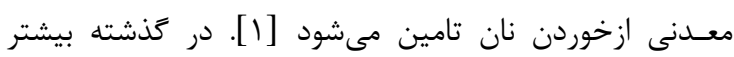

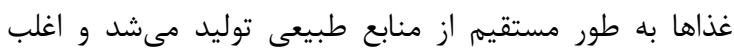
بدون هزينههاى جانبى به دست مصرف كننده مىرسيد، اما

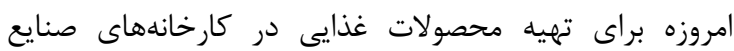

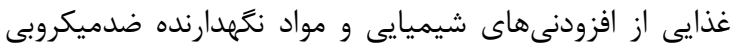

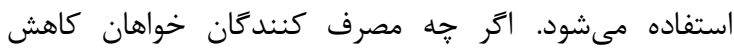


با از بين بردن آنتى اكسيدانها سبب تسريع در سرطان

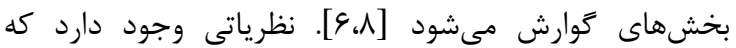

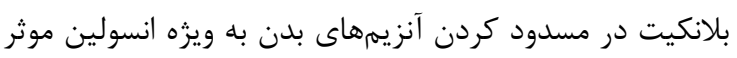

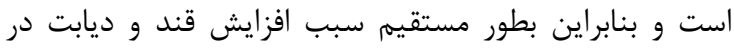

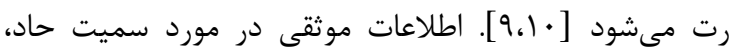
يوست، سوزش جشم، حساسيت و رتانسيل ايجاد جهشهاى

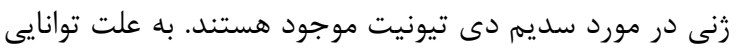

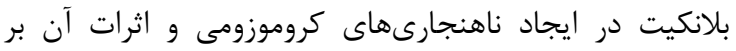

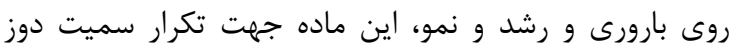

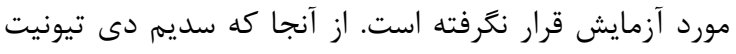

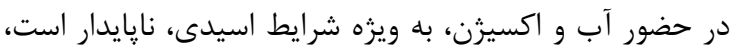

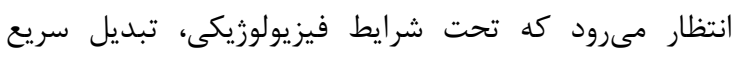
سديم دى تيونيت به گونههاى سولفيت (سولفيت، تيوسولفات

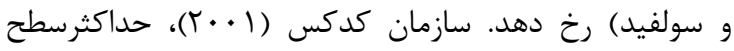

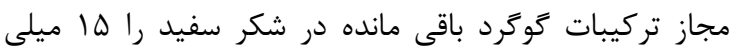

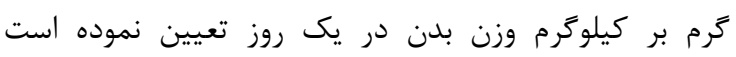

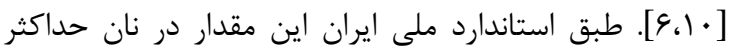

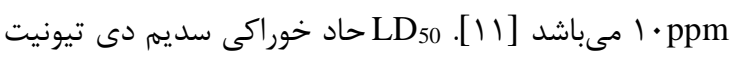

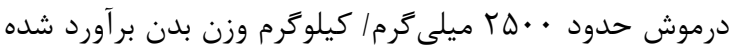

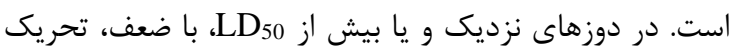

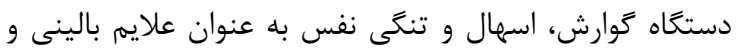

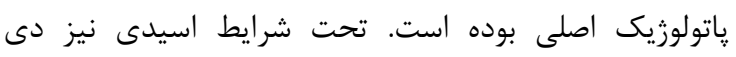

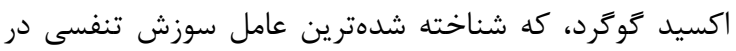

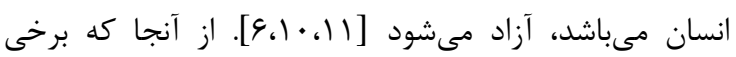

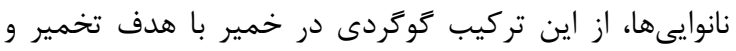

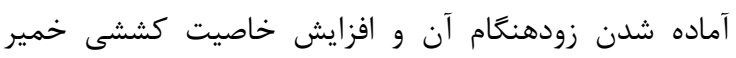

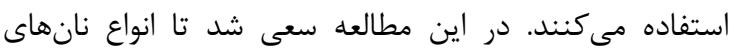
توليدى سطح شهرستان همدان از نظر استفاده غير مجاز از بلانكيت سنجيده شود. لذا هدف از اين مطالعه تعيين ميزان

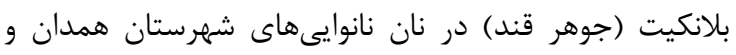

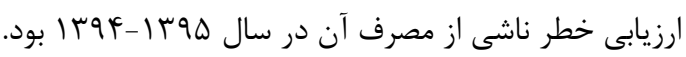

\section{مواد و روشها}

مطالعه حاضر يك مطالعه از نوع توصيفى-تحليلى با هدف تعيين ميزان غلظت بلانكيت در نان توليد شده در بران

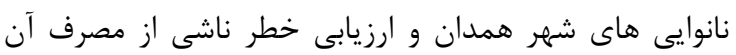

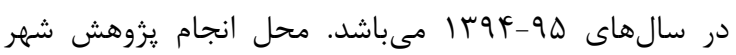
همدان و جامعه مورد بررسى تمام نانوايى هاى فعال در شهر

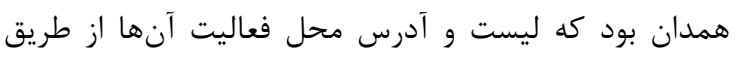

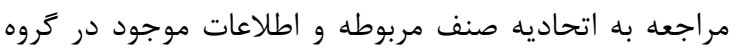

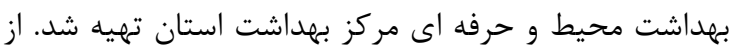

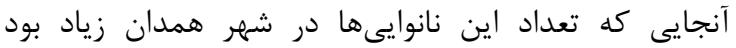

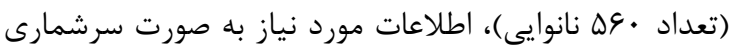

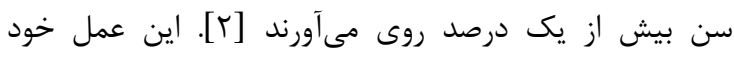

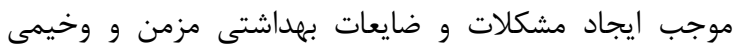
جون سوءهاضمه، اختلال در سيستم توارشى، سوءتغذيه،

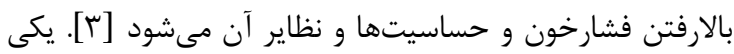

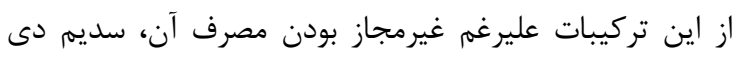

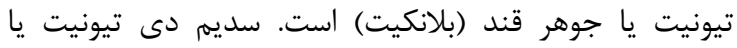

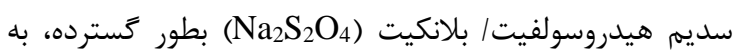
عنوان عامل سفيد كننده در صنايعى مثل خشك كردن مون مواد غذايى، قند، نساجى و كاغذ و رنكرزى فيبرهاى سلولزى استفاده

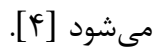

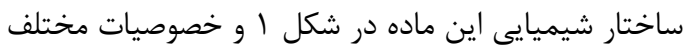
آن در جدول ا آورده شده است [هـئ.

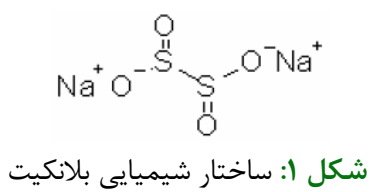

جدول ا: ويزگ هاى فيزيكى شيميايى بلانكيت [ع]

\begin{tabular}{|c|c|}
\hline مقدار & ويزَى \\
\hline جامد ل & وضعيت فيزيكى \\
\hline سفيد & رنغ \\
\hline$|V F /| \mid \mathrm{g} / \mathrm{mol}$ & وزن مولكولى \\
\hline$>9 \cdot{ }^{\circ} \mathrm{C}$ & نقطه ذوب \\
\hline$\Gamma / \Gamma \Lambda\left(T \cdot{ }^{\circ} \mathrm{C}\right)$ & دانسيته نسبى \\
\hline IAr g/L $\left(r \cdot{ }^{\circ} \mathrm{C}\right)$ & حلاليت در آب \\
\hline
\end{tabular}

واكنشهاى اين ماده در مجاورت آب در روابط زير آورده

شده است [ع]:

در شرايط بىهوازى

$2 \mathrm{NaHSO}_{3} 2 \mathrm{Na}_{2} \mathrm{~S}_{2} \mathrm{O}_{4}+\mathrm{H}_{2} \mathrm{O} \rightarrow \mathrm{Na}_{2} \mathrm{~S}_{2} \mathrm{O}_{3}+$

در شرايط هوازى

$2 \mathrm{NaHSO}_{3} \mathrm{Na}_{2} \mathrm{~S}_{2} \mathrm{O}_{4}+\mathrm{O}_{2}+\mathrm{H}_{2} \mathrm{O} \rightarrow$ $\mathrm{Na}_{2} \mathrm{~S}_{2} \mathrm{O}_{3}+$

در شرايط اسيدى

در صنايع توليدى قند و شكر، نبات و آبنبات نيز از ماده

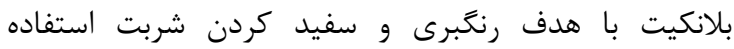

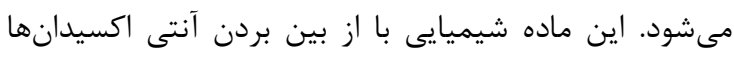

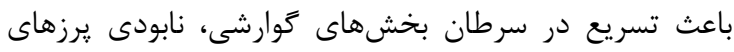

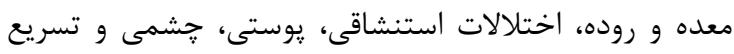

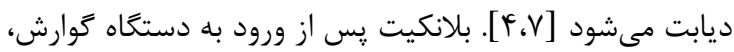

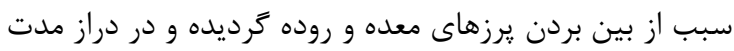


بعد از تعيين غلظت بلانكيت، ارزيابى خطر ناشى از مصرف نان به شرح زير انجام شد:

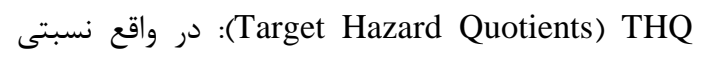
است ميان در معرض قرارگيرى مواد سمى و دز رفرنس آنها

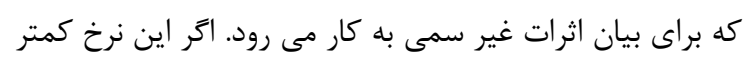

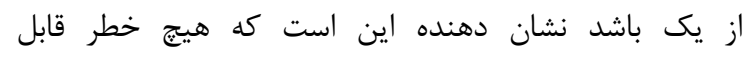

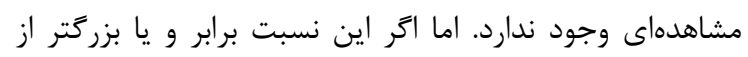

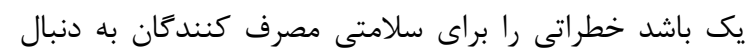

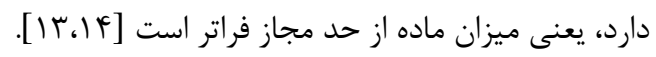

$\mathrm{THQ}=\frac{\mathrm{ADD}}{\mathrm{RFD}}$

THQ متوسط دوز دريافتى روزانه در طول دوره مواجهه (RFD) Reference Dose گرم بر كيلوگرم در روز)

$$
\mathrm{WI}=\frac{(G \times F I R W)}{B W}
$$

$$
\text { Week Intake) WI }
$$

كُفتر (Effective frequency) EF

$$
\text { كرفتن (هاء روز در سال) }
$$

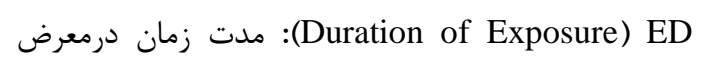

$$
\text { قرار گرفتن ( VT ساله براى بزرگسالان) }
$$

مص في نان (Frequency of bread Intake Rate) FIR

$$
\text { مصرف نان (كيلوگرم براى هر فرد در روز) غلظت بلانكيت در نان (mg/kg) }
$$

RfD

داض Average exposure time) ATn

$$
\text { درمعرض قرار زرفتن (ED×365) }
$$

V• (Average body weight) WAB

$$
\text { كيلوگرم براى بزرگسالان) }
$$

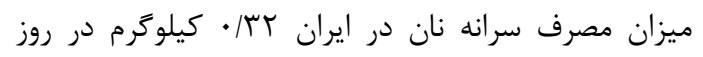

$$
\text { براى هر نفر مىباشد [11]. }
$$

$$
\mathrm{CR} l i m=\frac{(\mathrm{RFD} \times \mathrm{BW})}{\mathrm{Cm}}
$$

(Bread Usage Limit) CRlim

$$
\text { (كيلو亏رم در روز) }
$$

(mg/kg) غلظت بلانكيت در نان (m)

$\mathrm{CRmm}=\frac{(\text { CRlim } \times \text { Tap })}{\mathrm{Ms}}$

$$
\text { :CRmm }
$$

جمعآورى شد. لازم به ذكر است كه به هر نانوايى ب بار در

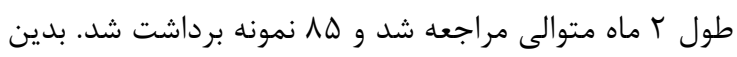

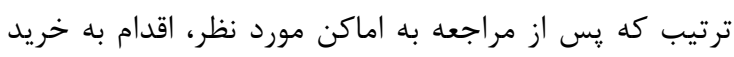

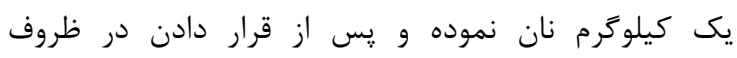
يلاستيكى و درج مشخصات محل نمونه بردارى و تاريخ به به نيه

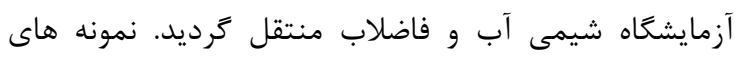

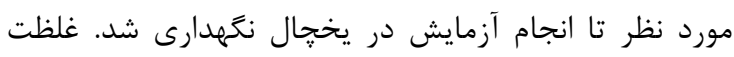

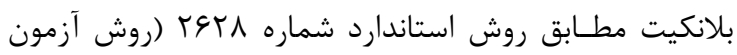

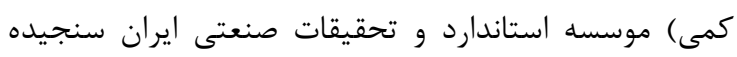
شد [11]]. جهت توجه به اثـر تـصادفى نـانوايىهــا از آنـاليز

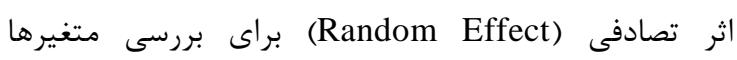

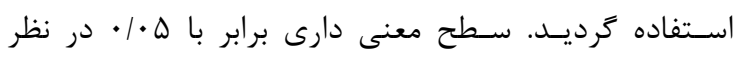

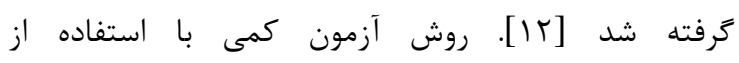

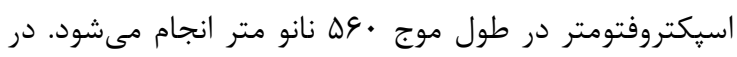

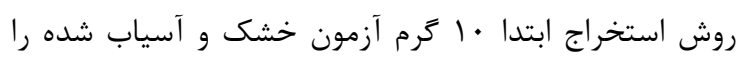

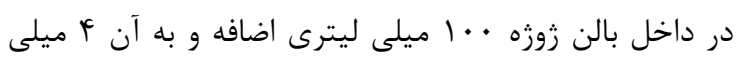

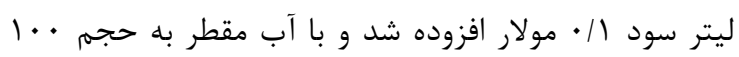

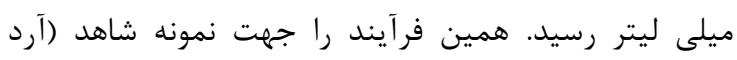

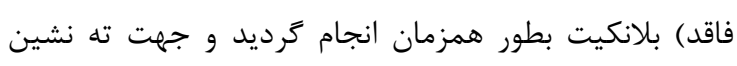

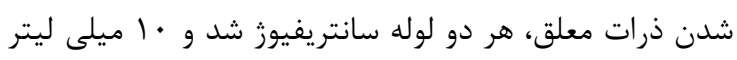

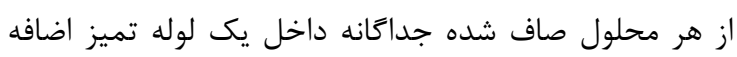

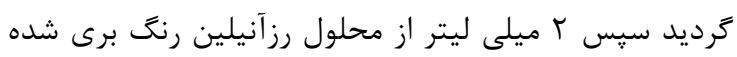

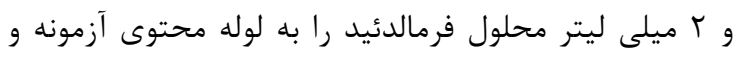

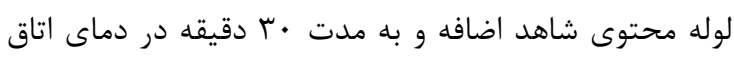

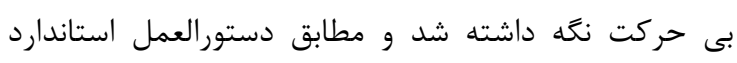

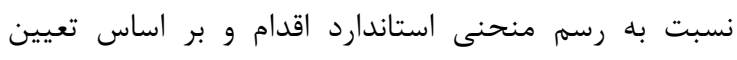

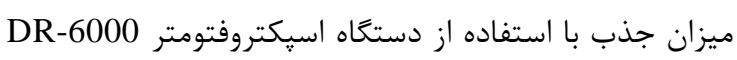

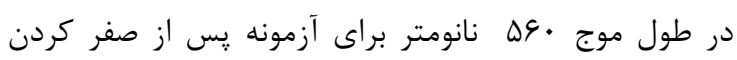
دستخاه با نمونه شاهد قرائت كرديد.

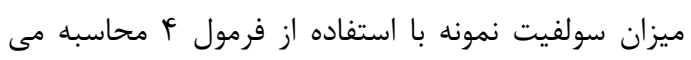
شود:

$C\left(\frac{g \mathrm{SO}_{2}}{\mathrm{~mol}}\right)=(25-V) \times 3.203 \times 2$

$$
\begin{aligned}
& \text { C مقدار سولفيت بر حسب ميكروگرم SO در ميلى ليتر } \\
& \text { V }
\end{aligned}
$$

$$
S O_{2}(p p m)=C \times \frac{10}{W}
$$

SO2

$$
\text { سولفورو در كيلوگرم آزمونه }
$$

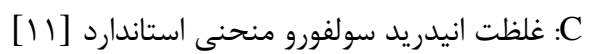


توليد شده در نانوايىهـا در جـدول ا نشـان داده شـده اسـت.

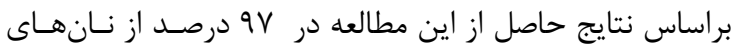

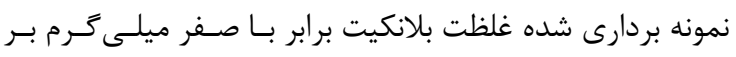

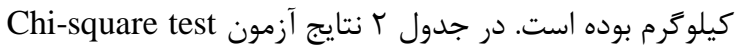

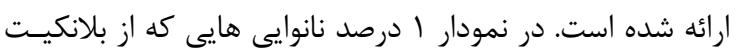
استفاده مى نمايند به تفكيك نوع نان ارائه شده است.
Average period of time) Tap ( ) ( (The amount of each serving) MS

يافتهها

مقادير غلظت بلانكيت در نمونههاى نان به تفكيك نوع نان

جدول rا: ميانگَين ميزان غلظت بلانكيت در نان توليدى شهر همدان به تفكيك نوع نان

\begin{tabular}{|c|c|c|c|c|c|}
\hline انحراف معيار & ميانتين & حداكثر & حداقل & تعداد & نوع نان \\
\hline$r / F G$ & - $\mid q 4$ & $1 \cdot / r$ & . & 4. & لواش \\
\hline · & . & - & . & IT & سنخَك \\
\hline · & $\cdot$ & - & · & $\wedge$ & بربرى \\
\hline$r / F^{f}$ & $\cdot \mid k \lambda$ & $1 \cdot / r$ & . & $\Lambda$. & كل \\
\hline
\end{tabular}

\section{جدول ب: تست Chi-square test}

\begin{tabular}{|c|c|c|c|c|c|}
\hline \multicolumn{2}{|c|}{ Pونت كارلو (r طرفه) } & \multirow[b]{2}{*}{ Pرض دوطرفه } & \multirow[b]{2}{*}{ فاصله اطمينان } & \multirow[b]{2}{*}{ 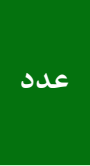 } & \multirow[b]{2}{*}{ آماره و آزمون } \\
\hline فاصله اطمينان 99 درصد & Pvalu & & & & \\
\hline 1 & 1 & $\cdot / V \cdot F$ & r & $\cdot / V \cdot T$ & آماره پِيرسون \\
\hline 1 & 1 & $\cdot / \Delta \Delta T$ & r & $1 / 1 \wedge \Delta$ & نسبت درستنمايى \\
\hline 1 & 1 & & & .1999 & آزمون دقيق فيشر \\
\hline \multirow[t]{2}{*}{$\cdot / V \Delta \varphi$} & $\cdot / V G V$ & . MFt & 1 & $\cdot / \Delta \wedge \Lambda$ & ارزيابى خط به خط \\
\hline & & & & ^. & تعداد داده \\
\hline
\end{tabular}

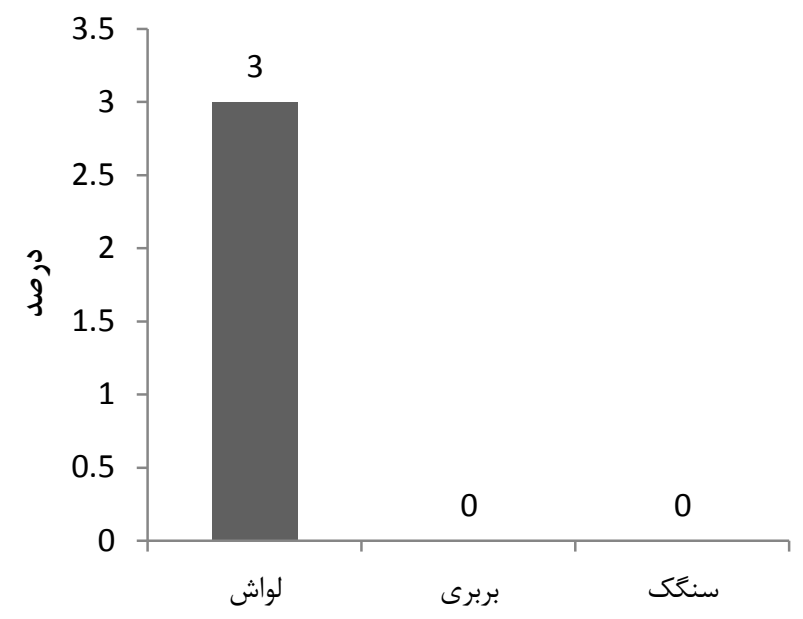

نمودار ا: درصد نانوايىهايى استفاده كننده از بلانكيت به تفكيك نوع نانوايى

(ويتامين C)، آسيارتام، بتاكاروتن، BHA يا هيدروكسى انيزول بوتيليتد و BHT يا هيدروكسى تولوئن بوتيلتيد از مهرمترين

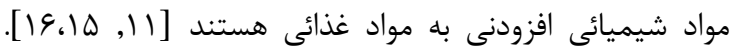

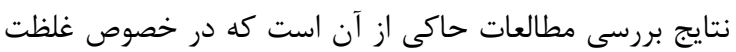
بلانكيت در نان در سطح بين المللى تحقيقى صورت نكرفته ان انس
امروزه آنتى اكسيدانها، امولسيفايرها، افزايش دهندههاى

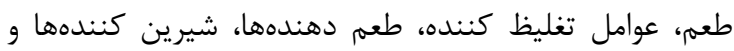

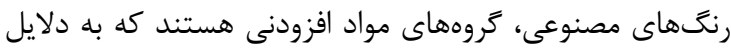
مختلف به مواد غذايى اضافه مىشوند. در اين ميان آسولفام

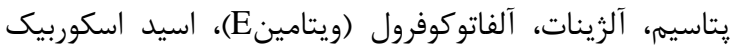


نتايج مطالعه ايشان از معنى دار نبودن غلظت در شيره انكور

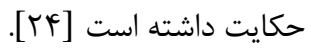

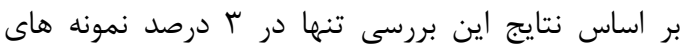

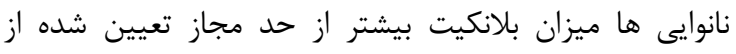

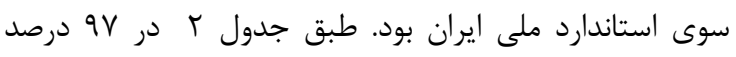

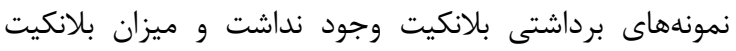

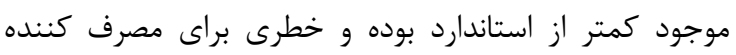

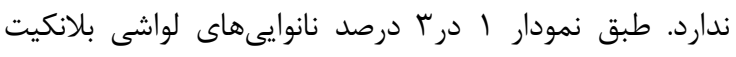

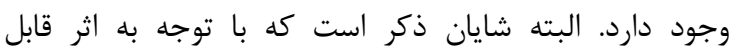

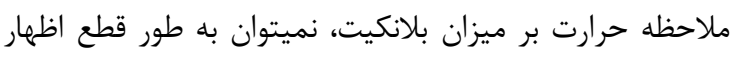

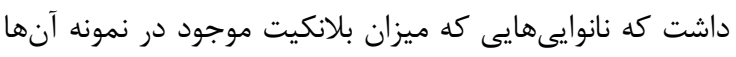
ناجيز است از اين تركيب شيميايى استفاده نكردهاند [1/1]

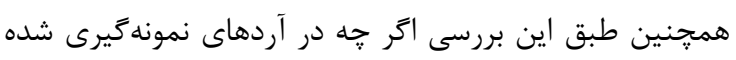

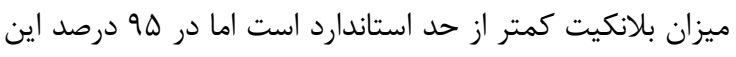

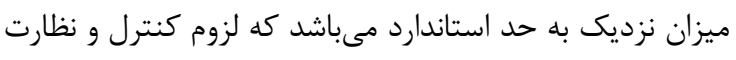

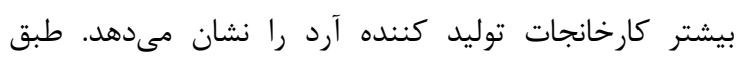

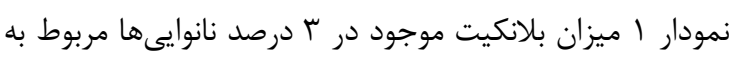

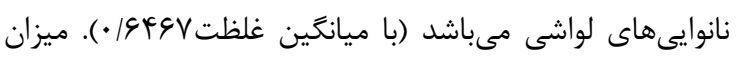

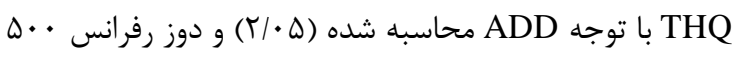

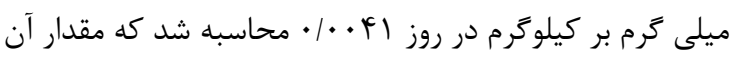

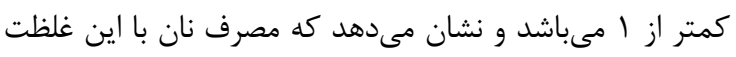

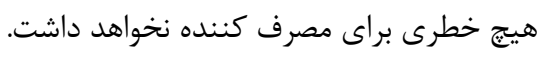

\section{نتيجه كيرى}

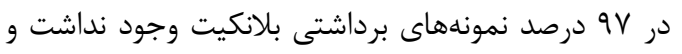

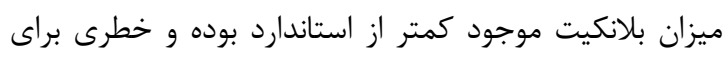

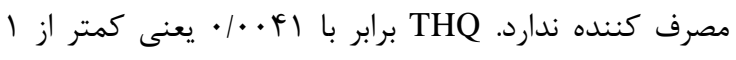

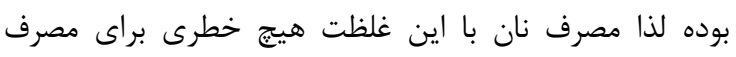

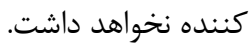

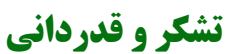

دزوهش حاضر با حمايت معاونت تحقيقات و فناورى

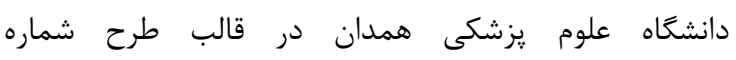

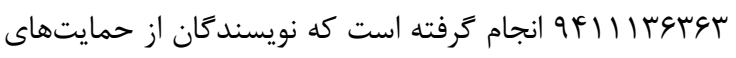

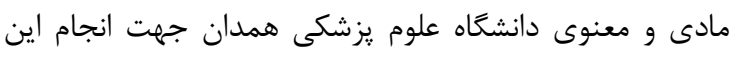
مطالعه تشكر و قدردانى مىنمايند.

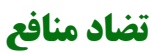

اين مطالعه براى نويسندكان هيجَّونه تضاد منافعى نداشته

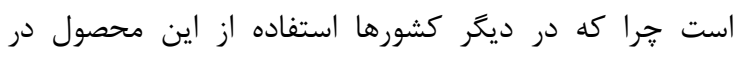
فراورى مواد غذايى ممنوع است. همجحنين امكان مقايسه نتايج

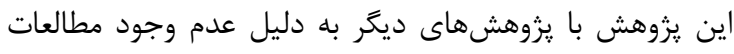

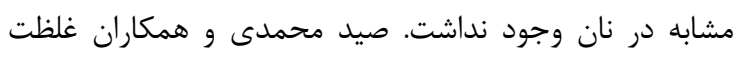

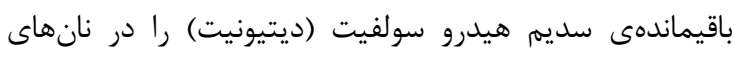

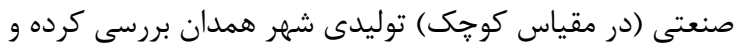

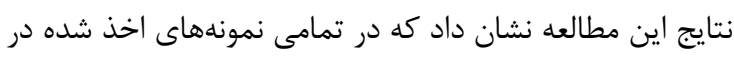

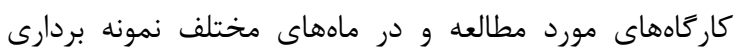

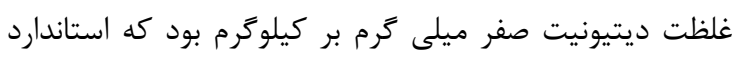

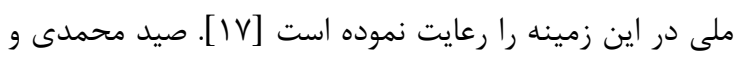

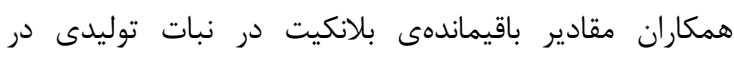

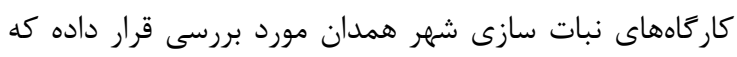

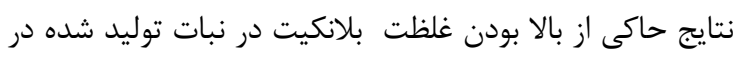

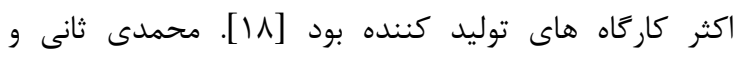

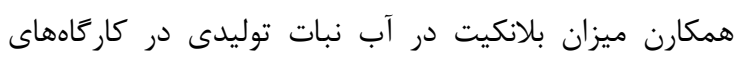

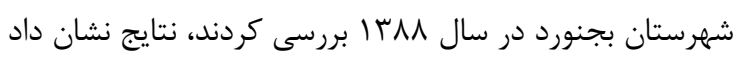

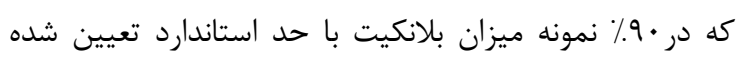

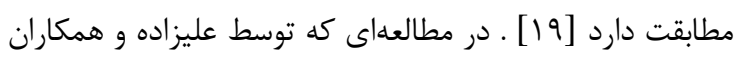

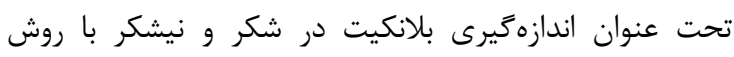

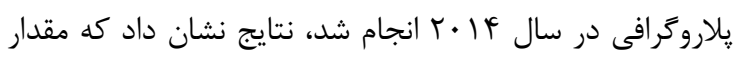

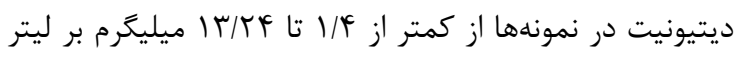

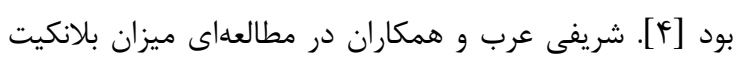

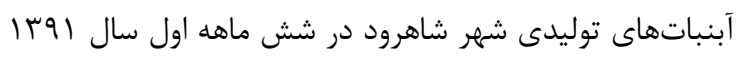

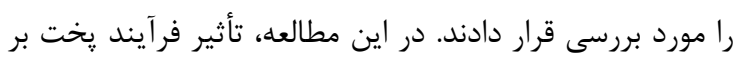

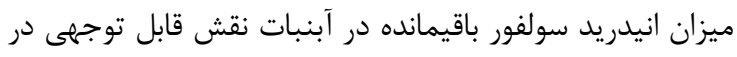

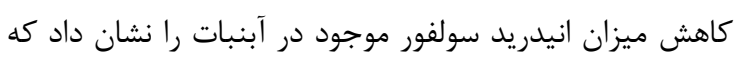

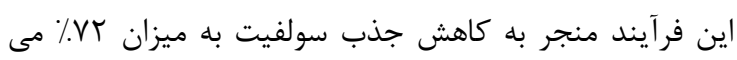

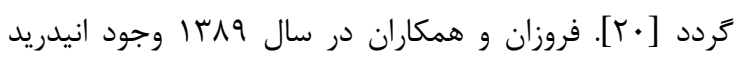

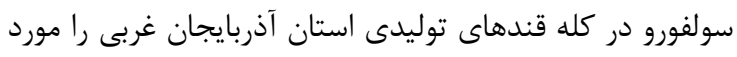

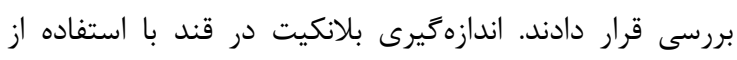

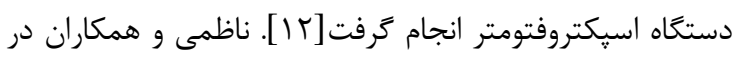

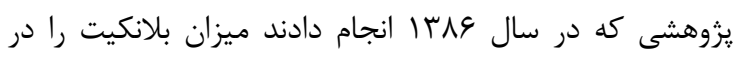

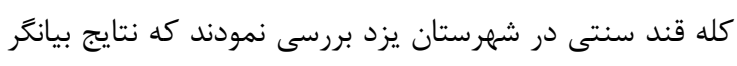

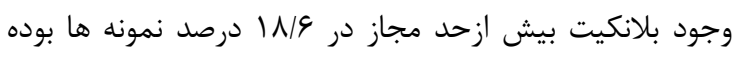

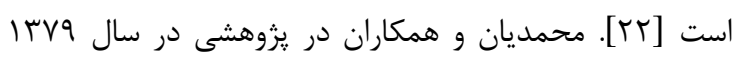

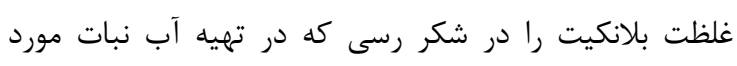

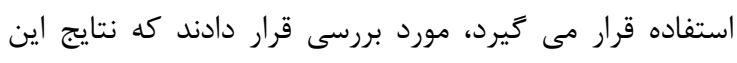

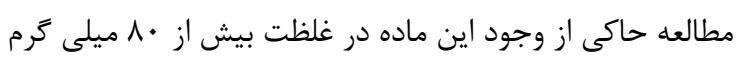

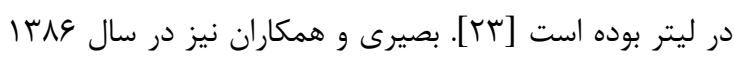

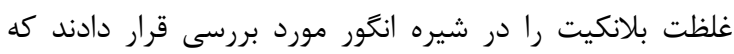

\section{REFERENCES}

1. Rezaei-Mofrad M R, Rangraz-Jeddi F,Mousavi G A. Amount of baking soda and salt in bakeries of Mehrdasht 
2. Khamirchi R, Tavana E, Arash A. Investigation of amount of soda and salt in bakeries of Sabzevar in 2006-2007. Journal of Sabzevar. 2010;17(2):135-42. (Persian)

3. Goodarzi B,Madani A, Soleimani M, Dindarlo K, Alipoor V. Hygiene status in urban bakeries of Bandar Abbas in 2012. Journal of Comparative Psychology. 2014;1(1):5-10. (Persian)

4. Alizadeh AM,Mohseni M, Zamani AA, Kamali K. Polarographic determination of sodium hydrosulfite residue (Dithionite) in sugar and loaf sugar. Food Analytical Methods. 2015;8(2):483-8. (Persian)

5. Weinrach JB, Meyer DR, Guy JT, Michalski P E, Carter K L, Bennett DW. Structural study of sodium dithionite and its ephemeral dihydrate: A new conformation for the dithionite ion. Journal of Crystallographic and Spectroscopic Research. 1992;22(3):291-301.

6. Bansal S, Singh A, Mangal M, Anupam K, Kumar S. Food adulteration: sources, health risks and detection methods, Critical Reviews in Food Science and Nutrition. 2017; 57 (6): 1174-1189.

7. Pena RJ. The influence of gluten proteins on the mixing and baking properties of four secondary hexaploid triticales. Manitoba, Canada: The University of Manitoba; 1984.

8. Cholamreza M. Fundamentals of sugar processing technology. Iran: Agriculture sciences; 2006. (Persian)

9. Vahidi AR, Afkhami. A M, Vahidi MY, Rezvani ME. Effect of Blankyt on Fasting Blood Sugar in Normal Rats. Journal of Yazd. 2012;3(12):161-7. (Persian)

10. Codex Alimentarius Commission. Codex standard for sugars. Roma: FAO-WHO; 1999. P. 5-10.

11. Iran IoSaIRo. Specifications and test methods for traditional breads. Iran: Institute of Standards and Industrial Research of Iran. 2014, 3: 1-9. (Persian)

12. J. Neter, M.H. Kutner, C.J. Nachtsheim, W. Wasserman, Applied Linear Statistical Models Irwin Chicago, 1996.

13. Kyriakoudi A, Ordoudi S, Roldan-M M, Tsimidou M. Saffron, A Functional Spice Austin Journal Nutrition and Food Sciences. 2015, 3:(1):1059-65.

14. Bouzembark Y, Marvin HJ. Prediction of food fraud type using data from rapid alert system for food and feed (RASFF) and bayesian network modelling. Food Control.
2016;61:180-7.

15. Ferré-Huguet N, Marti-CidR, Schuhmacher M, Domingo JL. Risk assessment of metals from consuming vegetables, fruits and rice grown on soils irrigated with waters of the Ebro river in Catalonia, Spain. Biological. Trace Element Research. 2008; 23: 66-79.

16. Brennan JG. Food Engineering Operations. 3td ed. New York: Elsevier Applied Science; 1990

17. Seidmohammadi A, Asgari Gh, Sharifi Z, Fardmal J, Yari Kh, Pirmoghani A .Study of the residual Sodium Hydrosulfite (Dithionite) levels in produced industrial breads: case study in Hamadan. Pajouhan Scientific Journal. 2017;15(3):23-28. (Persian)

18. Seidmohammadi A, Asgari G, Lotfi A, Fardmal J, Heshmati A, Pirmoghani A. Investigation of sodium dithionite residues in the rock candies produced in the candies making plants of Hamadan, Iran. Journal of health research in community. 2017;3(1): 1-8. (Persian)

19. Mohammadi sani A, Mohammadi F, Fayaz M. study on Balnkit in nabat in the Bojnord in 2009. Food Science and Technology. 2009;2(1):51-9. (Persian)

20. Sharifi GH, Beameri MA, Mohammadi M, Abasi N. Investigation of amount of Blankyt in candy produced in Shahrod city in 2010. Food Science and Technology. 2011;39 (10):118-202. (Persian)

21. Siedkhoei R Rad R, Dalirrad M, Forozan SH..Investigation of sulfur anhydride in sugar beet production in West Azarbayjan province in 2010, 20th National Congress of Food Science and Technology; September 10- September12; Mashhad 2010.

22. Nazemi A, Mali A. Study on blankit residues in cubicsugar produced in plants of Yazd City, Yazd, Iran: Institute of Standards and Industrial Research; 1998. (Persian)

23. Z M, Ghanaate K. Using cubic sugar industries contain high amount of balnkit for product alcohol atelic. First conference of applied biology, Mashad; Iran 1999. (Persian)

24. Sh B. Study on soil amount, blankit usage and type of grapes influence on grapes concentrated quality. Journal of science and agricultural industries. 2001;20(7):173-81. 